\title{
The Effect of Pulsed Electrodeposition Parameters on the Percentage of Gold and Thickness of the Gold-Copper Layers
}

\author{
Hamid Babaei ${ }^{1, *}$, Mohamad Reza Sovizi ${ }^{2}$, Morteza Khosravi ${ }^{3}$, Saeed Abedini Khorami ${ }^{4}$ \\ ${ }^{1}$ Faculty of Chemistry, Islamic Azad University, tnb, Tehran, I.R. of Iran \\ ${ }^{2}$ Department of Chemistry, Malek Ashtar Industrial University, Tehran, I.R. of Iran \\ ${ }^{3}$ Faculty of Chemistry, Islamic Azad University, tnb, Tehran, I.R. of Iran \\ ${ }^{4}$ Faculty of Chemistry, Islamic Azad University, tnb, Tehran, I.R. of Iran \\ *E-mail: h babaei@iau-tnb.ac.ir
}

\begin{abstract}
The results of this study indicated the optimization of the effective parameters in fixing the percentage of gold and thickness of Au-Cu alloy on the pure silver electrode. This method included specific parameters such as the average current density, duty cycle percentage, bath temperature, concentration of gold and cyanide ions in electrolyte, $\mathrm{pH}$, stirring of electrolyte and the wetting agent additive for obtaining gold percentage with standard $18 \mathrm{~K}$ standard carat $(75 \%$ gold and $25 \%$ Copper) which have been optimized effectively using "one- factor- at a- time" method. Under optimum conditions and fixing up the percentage of gold in the alloy, along with changes in the duty cycles $(20 \%$ to $90 \%)$, the thickness of the layers was also optimized. The thickness of the cross sections of the co-deposited samples and the percentage of gold in the deposits were investigated by SEM-EDX, XRF, and ICP-OES. Optimum conditions were determined regarding the amount of gold co-deposited with copper and the thickness of deposits. The results showed that the $\mathrm{Au}-\mathrm{Cu}$ alloy electro-deposited layer in the 30\% duty cycle and the average current density by $0.6\left(\frac{\mathrm{mA}}{\mathrm{cm}^{2}}\right)$ was as the layer formed in optimal conditions with 74.4 wt. \% gold and with $202 \mu \mathrm{m}$ electro-deposit thickness.
\end{abstract}

Keywords: Electro-deposition, Average current density, One-factor- at- a- time method, Optimization of $\mathrm{Au}-\mathrm{Cu}$ alloys, Duty cycle, Electro-deposit thickness, Percentage of gold

\section{1-Introduction}

The electrodeposition facilitates the control of experimental parameters including the electrolytic composition, deposition temperature, applied current density, load to be deposited and $\mathrm{pH}$ of the solution [1]. It is a highly suitable method for fabricating such structures as it allows deposition of metals with much larger thickness and better morphology than that achieved by physical deposition. The electrochemical deposition of gold is one of the methods for producing hollow gold jewelry with various karats [2]. The microstructure in electrodeposited metals can be controlled by different deposition parameters like bath temperature, solution $\mathrm{pH}$ and applied current density [3]. Gold alloy layers with standard karats of $9 \mathrm{~K}$ to $22 \mathrm{~K}$, which are formed by the electrochemical deposition method, are characterized by a specific gold percentage, mechanical properties, hardness and flexibility for making hollow gold jewelry. Initially, the $\mathrm{Au}-\mathrm{Cu}-\mathrm{Cd}$ baths were created because cadmium was used as a brightening agent in a solution of $\mathrm{Au}-\mathrm{Cu}$ alloying electrolytes. The bath was widely used in the production of hollow artifacts of gold and watch cases with different percentages of gold in the alloy. These layers were very shiny, uniform, ductile and also, they were capable of creating high thicknesses about 300-500 $\mu \mathrm{m}$ [4-5]. The color of the layers resulting from the electrochemical deposition of gold and copper is often the same as the color of the alloy produced by the metallurgical method. The addition of the third element is considered as the main problem, because, the brightening and uniformity of the surface layer should be maintained in addition to the color and gold percentage in the alloy. In creating thick gold and alloys in the production of hollow gold jewelry [6-7], due to cadmium toxicity, this element is removed from the $\mathrm{Au}-\mathrm{Cu}$ of the basic things gradually.

One of the goals regarding the use of pulse current is to reach the desired thickness by maintaining the percentage of alloying elements as well as its mechanical properties. Electrochemical deposition with pulsed current has provided a great opportunity for extensive research not only in the industry of producing hollow artifacts, but also in the electronics, aerospace and automotive industries [8-9]. Some of the most important advantages of electrochemical deposition using pulsed current, especially in forming the thick layers, include increasing the deposition efficiency, creating higher density and fine-grained layers. The changes are much less in the thickness of the layers at different points of the surface which indicates the less need for organic additives rather than direct current [10]. The use of pulsed current provides the basis for creating a denser layer rather than direct current, which results in an increase in nucleation and formation of fine-grained layers [11-12]. Furthermore, increasing 
the current results in the surface roughness [13-14]. In deposition by direct current, the current density is the only variable parameter, but in pulsed electrochemical deposition, there are at least three parameters including the pulse height $\left(\mathrm{I}_{\mathrm{p}}\right)$, off-time and on-time time, which can be found in various electro-chemical deposition processes for optimization. Typically, the pulse illumination time can vary from 1.0 to 9.9 milliseconds and the pulse power off time may vary from 1 to 99 milliseconds. The average current density is obtained using an ammeter. In order to have the same deposition rate using pulse current instead of direct current, the average current density should be equal to direct current [15].

Given the pulse current at any moment, the current density and the pulse duration can be adjusted. By selecting the pulse parameters for the electrochemical deposition of metals and alloys carefully, the physical and chemical properties of the deposited layers can be controlled very carefully. Having adjusted the pulse current parameters, a significant increase would be achieved in the thickness of the layer compared to the direct current at the same values of electricity from the electrolyte [7]. During pulse electro-deposition, the percentage of duty cycle $(\% \theta)$ represents the percentage of total pulse cycle time [7] and it is calculated by the following equation:

$$
\% \text { Duty Cycle }=\frac{t_{\text {on }}}{t_{\text {on }}+t_{\text {off }}} \times 100
$$

In the pulsed electrochemical deposition process, the average flow density $\left(\mathrm{I}_{\mathrm{avg}}\right)$ is :

$$
\mathbf{I}_{\text {avg }}=\mathbf{I}_{\mathbf{p}_{\mathbf{t}_{\text {on }}}+\mathbf{t}_{\text {off }_{\text {ff }}}}
$$

Which $I_{\text {avg }}$ and $I_{p}$ are the mean values of the average current density and pulse current density [7].

The theory thickness ( $\mathrm{T}_{\text {theory }}$ ), in micrometers, also follows from the relation

$$
\mathbf{T}_{\text {th }}=\frac{\mathbf{m}_{\mathrm{a}} \times \mathbf{1 0 ^ { 4 }}}{\mathbf{A} \times \boldsymbol{\rho}_{\text {alloy }}}
$$

It is calculated that $m_{a}$ is the mass of the deposited layer in grams; A is the cathode surface area in $\mathrm{cm}^{2}$ and $\rho_{\text {alloy }}$ , is the density of the deposited layer in grams per cubic centimeter [16]. $\rho_{\text {alloy }}$ Is obtained from the following relationship :

$$
\frac{1}{\rho_{\text {alloy }}}=\frac{f_{\text {Au }}}{\rho_{\text {Au }}}+\frac{f_{\mathrm{Cu}}}{\rho_{\mathrm{Cu}}}
$$

In the above relation, $\rho_{\mathrm{Au}}$ and $\rho_{\mathrm{Cu}}$ are the density of gold and copper whose value are equal to $\rho_{\mathrm{Au}}=19.3 \frac{\mathrm{gr}}{\mathrm{cm}^{3}}$ and $\rho_{\mathrm{cu}}=8.96 \frac{\mathrm{gr}}{\mathrm{cm}^{3}}$, as well as $\mathrm{f}_{\mathrm{Au}}$ and $\rho_{\mathrm{Cu}}$ that are the components of weighted gold and copper deposited in the layer [2]. Using the results obtained by scanning emission microscopy (SEM), the average thickness of the layers obtained in experimental study was compared with theoretical values, and the percentage of the formation of the layers $(\% \varepsilon)$ was calculated by the following equation:

$$
\% \varepsilon=\frac{\mathrm{T}_{\text {avg }}}{\mathrm{T}_{\text {th }}} \times 100
$$

$\mathrm{T}_{\text {avg }}$ and $\mathrm{T}_{\text {th }}$ are the average thicknesses of the layer obtained and calculated regarding thickness of the theory in micrometers [16].

In electro-deposition with the same values of electricity, the pulse current would be thicker than direct current. By applying the specified potential value during a pulse cycle, at the Off-time of pulse, the potential decreases slightly. Hence, electrochemical reduction is observed over the period of Off-time [9].

In this research, firstly, the parameters of direct and pulsed current density (with $10 \%$ duty cycle), bath temperature, concentration of gold and cyanide in solution, $\mathrm{pH}$, agitation speed and additive effect were optimized by the "one- factor- at- a- time" method [17], in order to reach the standard percentage of gold in the sample (Wt.75\% Au and wt.\% $25 \mathrm{Cu}$ ). After fixing the percentage of gold in the layers, changes in the percentage of duty cycle (20\% to $90 \%)$ were investigated in order to achieve the optimal thickness of the alloy layer.

The analysis and determination of the exact amount of Au in alloys of gold artifacts were carried out using the standard method called copulation. New developments in the field of ICP spectrometry, which were more specific for precious metals, suggested that the mentioned technique could be regarded as a suitable alternative to copulation. The precision, speed and the possibility of simultaneous analysis of several metals in alloys of gold artifacts were the advantages of this method compared to copulation. The use of ICP to determine the values of precious metals in gold artifacts could be confirmed only if the results of this method had an error rate of less than $0.1 \%$. In particular, in order to determine the amount of gold in alloys of gold artifacts, the amount of gold should be focused more than all other alloying elements [18]. 


\section{2-Materials and Methodology}

Potassium Cyanide, Copper (I) cyanide, Lauryl dimethyl amine oxide (LDAO), Sodium hydroxide and Sulfuric acid were purchased from Merck and Potassium gold cyanide was purchased from Umicore GmbH.

An electro-deposition bath was a Pyrex beaker with a diameter of $110 \mathrm{~mm}$ and a height of $140 \mathrm{~mm}$ in the volume of 1 liter. The temperature control in the bath was performed using an IKA C-MAG HS7 heater with an accuracy of \pm 0.1 . The anodes were platinum-titanium mesh beads with dimensions of $80 \times 100$ millimeter, which were fixed in the beaker wall. Pure silver was prepared by casting as a cathode in the dimensions of $1 \mathrm{~cm}^{2}$ and thickness of $1 \mathrm{~mm}$, and then the finishing and polishing operations were done [4]. The bath agitation was carried out by a magnetic stirrer. The $\mathrm{pH}$ of the bath was also adjusted by the HANNA HI $98107 \mathrm{pH}$ meter.

All experiments were performed by the pulsed power supply of the SL20 PRC switch mode, made in Iran. The current density (pulse and direct) in the range of 2-12 $\frac{\mathrm{mA}}{\mathrm{cm}^{2}}$ was used to create the layers with a specific gold percentage and also to investigate the thickness of the layers. Weighing the samples was carried out using the Sartorius GK1203 analytical balance with a precision of $0.0001 \mathrm{~g}$ before and after electro-deposition.

The Au-Cu alloy bath was prepared by the composition listed in Table 1 [19-20].

Table 1. Electrodeposition bath composition of $\mathrm{Au}-\mathrm{Cu}$

\begin{tabular}{|c|c|}
\hline Electrolyte concentration range $(\mathrm{g} / \mathrm{l})$ & Components \\
\hline $18-25$ & $\mathrm{KCN}$ \\
\hline $5-10$ & $\mathrm{KAu}(\mathrm{CN})_{2} .68 .2 \mathrm{wt} \%$ \\
\hline 55 & $\mathrm{CuCN}$ \\
\hline 0.5 & $\mathrm{C}_{14} \mathrm{H}_{31} \mathrm{NO}$ \\
\hline
\end{tabular}

Before the electrodeposition, the samples were degreased out by special silver degreasing chemical, and were rinsed by ion-free water. They were neutralized using $5 \%$ sulfuric acid solution and finally were washed by double rinsed ion-free water [4]. After this step, the samples were electro-deposited under the conditions listed in Table 2.

Table 2. Conditions for the $\mathrm{Au}-\mathrm{Cu}$ electro-deposition

\begin{tabular}{|c|c|}
\hline Used range & Parameter \\
\hline $2-12\left(\mathrm{~mA} / \mathrm{cm}^{2}\right)$ & Current ensity $\left(\mathbf{m A} / \mathbf{c m}^{2}\right)$ \\
\hline $60-70\left({ }^{\circ} \mathrm{C}\right)$ & Bath Temperature \\
\hline $11.5-12.5$ & pH \\
\hline $50-175(\mathrm{rpm})$ & Agitation \\
\hline
\end{tabular}

The $\mathrm{pH}$ of the solution was adjusted using $10 \% \mathrm{NaOH}$ and $5 \% \mathrm{H}_{2} \mathrm{SO}_{4}$. In this study, firstly, the parameters of direct and pulsed current density (with a working cycle of $10 \%$ ), the concentration of gold and cyanide ions, the bath temperature, $\mathrm{pH}$, agitation and the amount of additive for creating the $\mathrm{Au}-\mathrm{Cu}$ alloy layers containing wt.\% 75 gold standard value were optimized by one- factor- at- a- time method. Then, using a constant Au percentage in the alloy, the thickness of the layers was optimized by changing the different duty cycle parameters. Pulse on and off time parameters were set at 0.01 seconds [15]. Thickness measurement of formed layers was done by the SEM CamScan MV2300 scanning electron microscope equipped with EDXBruker XFlash6110 in order to determine the percentage of elements in the alloy accurately. The exact amount of gold in $\mathrm{Au}-\mathrm{Cu}$ alloy deposits was investigated by inducing the coupler plasma spectrometry by ICP-OES, Varian 710, and X-ray fluorescence XRF Fischer scope ${ }^{\circledR}$ X-RAY XAN® 220 diffraction compared

\section{3-Results and Discussion}

The values of the parameters obtained in the optimization of direct and pulsed current deposition are summarized in Table 4 in order to create the deposited layers with the value of $75 \% \mathrm{wt}$. Au in alloy. 
Table 3. Optimized conditions electrochemical deposition of $\mathrm{Au}-\mathrm{Cu}$ alloy with direct current and pulse with $10 \%$ working cycle for stabilization of wt. $\% 75$ gold per alloy

\begin{tabular}{|c|c|c|c|c|c|c|c|}
\hline $\begin{array}{l}\text { C.D } \\
\left(\frac{\mathbf{m A}}{\mathbf{c m}^{2}}\right)\end{array}$ & $\begin{array}{c}\mathbf{C}_{\mathrm{Au}^{+}} \\
\left(\frac{\mathbf{g r}}{\mathbf{l}}\right)\end{array}$ & $\begin{array}{l}\mathrm{C}_{\mathrm{Cu}^{+}} \\
\left(\frac{\mathbf{g r}}{\mathbf{l}}\right)\end{array}$ & $\begin{array}{l}\mathrm{C}_{\mathrm{CN}^{-}} \\
\left(\frac{\mathbf{g r}}{\mathbf{l}}\right)\end{array}$ & $\begin{array}{c}\text { Agitation } \\
\text { (rpm) }\end{array}$ & $\begin{array}{l}\text { Temp } \\
\left({ }^{\circ} \mathrm{C}\right)\end{array}$ & pH & $\begin{array}{l}\text { Additive } \\
\qquad\left(\frac{\mathrm{ml}}{\mathrm{l}}\right)\end{array}$ \\
\hline 6 & 66 & 55 & 24 & 100 & 66 & 22 & 1 \\
\hline
\end{tabular}

In the electro-deposition of $\mathrm{Au}-\mathrm{Cu}$, the percentage of alloying elements and the thickness of the formed layer were influenced by various parameters, and in particular they were influenced by the current density. In fixed deposition conditions, if the same amount of current density was used, the pulse current would be increased significantly compared to direct current [7].

Figures 1 and 2 show the SEM image and EDS analysis of the cross section of Au-Cu deposited layers with direct and pulsed currents, both of which were identical in terms of optimal conditions and with a direct current density of $6 \frac{\mathrm{mA}}{\mathrm{cm}^{2}}$ and the average thickness of the alloying layer which was about $82 \mu \mathrm{m}$ and also with the $73.3 \mathrm{wt} . \%$ of gold. However, the average thickness of the layer produced by the pulse current was about 151 micrometers and with 74.4 wt. $\%$ of gold.
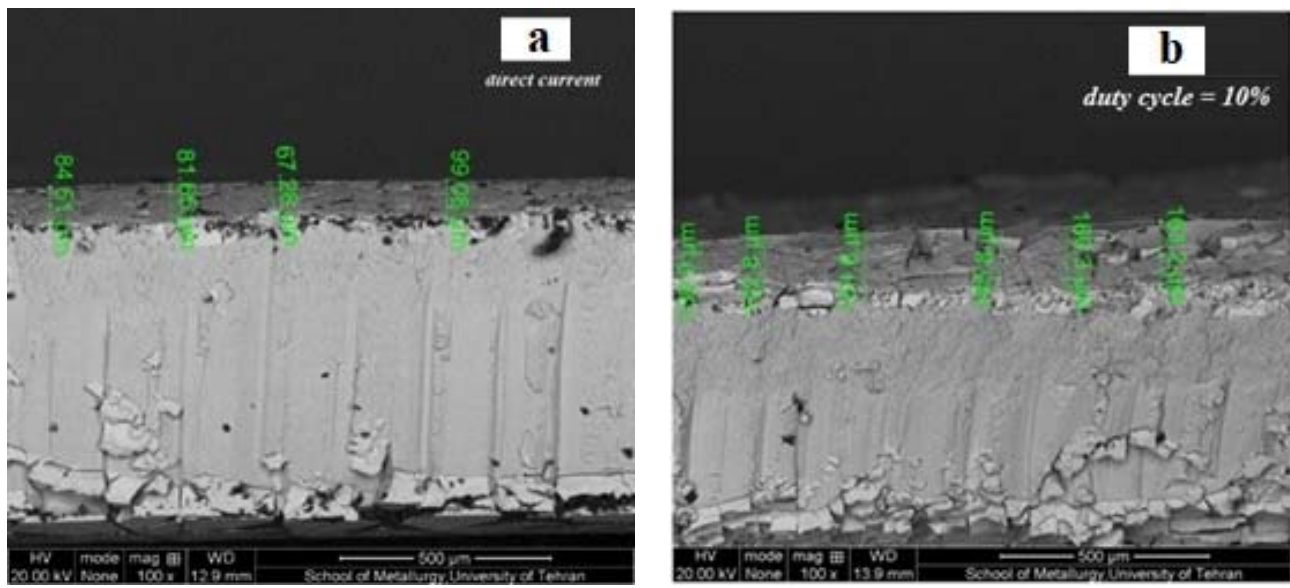

Fig. 1 SEM image of the cross-section of deposited samples to measure the average thickness of the layers, $82 \mu \mathrm{m}$ with direct current (a), $151 \mu \mathrm{m}$ with pulse current and $10 \%$ cyclic cycle (b).
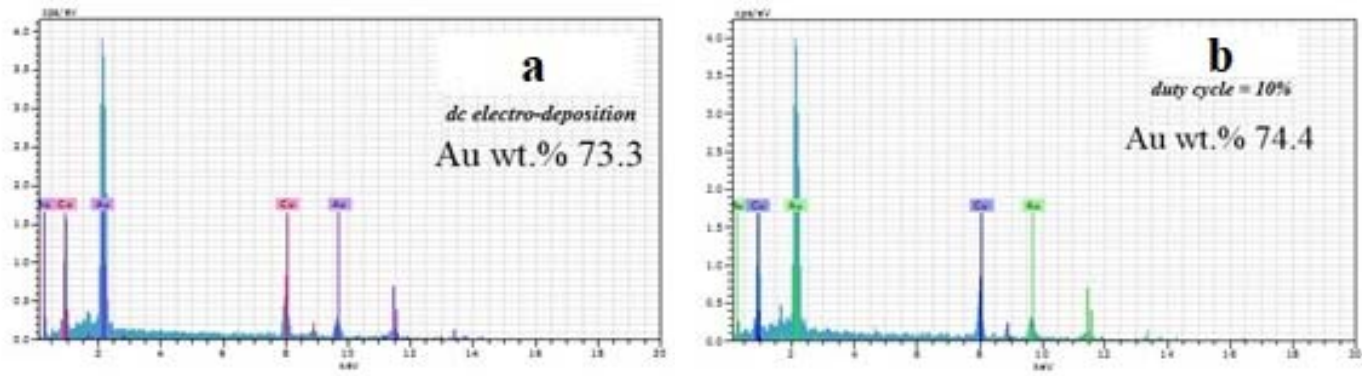

Fig. 2 EDS analysis of cross section of deposited samples to measure the amount of gold in the layers, wt. $73.3 \%$ by direct current (a) w / w\% 74.44 with pulse current and $10 \%$ (b).

Tables 5 and 6 show the effect of direct and pulse current on the mass of the layers, the percentage of gold, the current efficiency and thickness of the $\mathrm{Au}-\mathrm{Cu}$ layers formed in the 240 minute period under optimum conditions.

Table 4. The effect of direct current density on mass, gold percent and thickness of layer in 240 minute under optimum conditions

\begin{tabular}{|c|c|c|c|c|c|c|c|c|}
\hline \multirow{2}{*}{$\begin{array}{c}\text { C. D } \\
\left(\frac{\mathbf{m A}}{\mathbf{c m}^{2}}\right)\end{array}$} & \multirow{2}{*}{$\begin{array}{l}\mathbf{m}_{\text {alloy }} \\
\text { (mgr) }\end{array}$} & \multicolumn{2}{|c|}{ Alloy (\%) } & \multirow{2}{*}{$\begin{array}{c}\mathrm{A} \\
\left(\mathrm{cm}^{2}\right)\end{array}$} & \multirow{2}{*}{$\begin{array}{l}\rho_{\text {alloy }} \\
\left(\frac{\mathrm{gr}}{\mathrm{cm}^{3}}\right)\end{array}$} & \multirow{2}{*}{$\begin{array}{c}\mathrm{T}_{\mathrm{th}} \\
(\mu \mathrm{m})\end{array}$} & \multirow{2}{*}{$\begin{array}{r}\mathrm{T}_{\text {avg }} \\
(\mu \mathrm{m})\end{array}$} & \multirow{2}{*}{$\begin{array}{c}\tau \\
(\min )\end{array}$} \\
\hline & & $\mathbf{A u}$ & $\mathbf{C u}$ & & & & & \\
\hline 6 & 82.327 & 733 & 267 & 1 & 14.49 & 88 & 82 & 240 \\
\hline
\end{tabular}


Table 5. The effect of average pulse current density on mass, gold percent and thickness of layer in 240 minutes under optimum conditions

\begin{tabular}{|c|c|c|c|c|c|c|c|c|c|}
\hline \multirow{2}{*}{$\begin{array}{c}\boldsymbol{\theta} \\
(\%)\end{array}$} & \multirow{2}{*}{$\begin{array}{c}\mathbf{I}_{\text {avg }} \\
\left(\frac{\mathbf{m A}}{\mathbf{c m}^{2}}\right)\end{array}$} & \multirow{2}{*}{$\begin{array}{c}\mathbf{m}_{\text {alloy }} \\
\text { (gr) }\end{array}$} & \multicolumn{2}{|c|}{ Alloy(\%) } & \multirow{2}{*}{$\begin{array}{c}\mathbf{A} \\
\left(\mathbf{c m}^{2}\right)\end{array}$} & \multirow{2}{*}{$\begin{array}{l}\rho_{\text {alloy }} \\
\left(\frac{\mathrm{gr}}{\mathrm{cm}^{3}}\right)\end{array}$} & \multirow{2}{*}{$\begin{array}{c}\tau \\
(\min )\end{array}$} & \multirow{2}{*}{$\begin{array}{c}T_{\text {th }} \\
(\mu \mathrm{m})\end{array}$} & \multirow{2}{*}{$\begin{array}{r}T_{\text {avg }} \\
(\mu \mathrm{m})\end{array}$} \\
\hline & & & $\mathbf{A u}$ & $\mathrm{Cu}$ & & & & & \\
\hline 10 & 0.6 & 153.211 & 744 & 256 & 1 & 14.92 & 240 & 160 & 151 \\
\hline
\end{tabular}

The Au-Cu formed layers in the duty cycle of $30 \%$, had a thickness of $0.841 \mu \mathrm{m}$ and also contained 74.4 wt. $\%$ of gold in the alloy, which was more than the amount of alloy gold obtained in some of the commercial processes of the jewelry and watch case electroforming [21]. In duty cycles more than $30 \%$, a significant decrease was observed in the thickness of the $\mathrm{Au}-\mathrm{Cu}$ alloy that was formed in the same conditions. Increasing the duty cycle meant reducing the off-time. If the pulse time was too short, the electrical double layer wouldn't have enough growth opportunity, it would be very thin and in fact, there would be no difference using the mode of direct current [7]. Figure 4 and 5 show microanalysis of SEM-EDX of all the electro-depositions with various duty cycles ranging $20-90 \%$ of the samples cross sections that were at the same values of operation condition.


Fig.4. EDS micrographs of Au-Cu alloy analysis in the electro-deposits (a to $\mathrm{h}$ ) at same operation condition, at $20 \%$ duty cycle contents $73.2 \% \mathrm{Au}(\mathrm{a}) 30 \%$ duty cycle contents $74.4 \% \mathrm{Au}$ (b) $40 \%$ duty cycle contents $73.5 \% \mathrm{Au}$ (c). $50 \%$ duty cycle contents $72.7 \% \mathrm{Au}$ (d) and $60 \%$ duty cycle contents $74.3 \% \mathrm{Au}$ (e) $70 \%$ duty cycle contents $73.1 \% \mathrm{Au}$ (f) $80 \%$ duty cycle contents $72.7 \% \mathrm{Au}$ (g) and $90 \%$ duty cycle contents $74.0 \% \mathrm{Au}(\mathrm{h})$. 

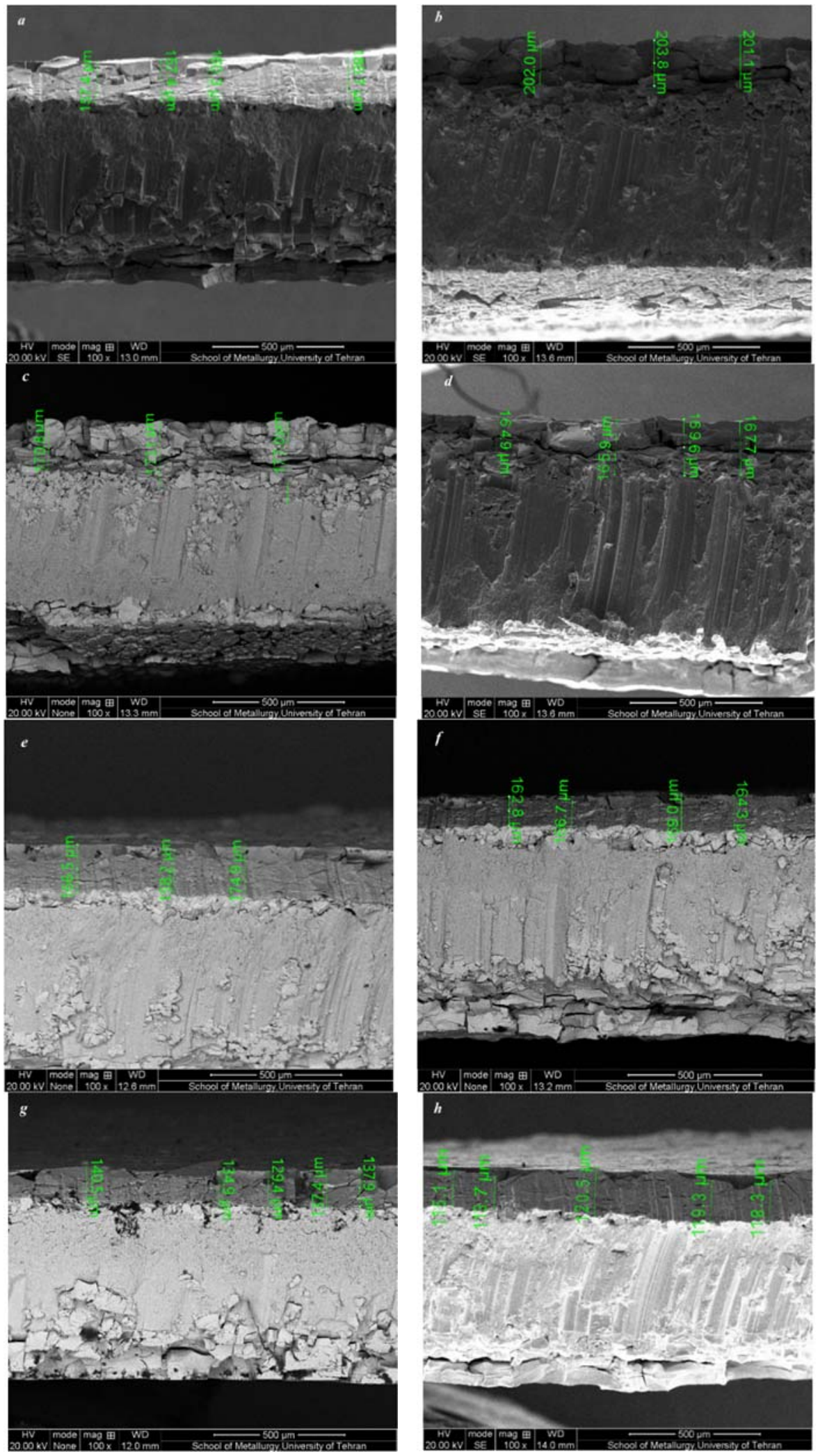

Fig.5. SEM cross section images of Au-Cu alloy (a to $\mathrm{h}$ ) at same operation condition, at $20 \%$ duty cycle contents $162 \mu \mathrm{m}$ (a) $30 \%$ duty cycle contents $202 \mu \mathrm{m}$ (b) $40 \%$ duty cycle contents $174 \mu \mathrm{m}$ (c). $50 \%$ duty cycle contents $167 \mu \mathrm{m}$ (d) and $60 \%$ duty cycle contents $166 \mu \mathrm{m}$ (e) $70 \%$ duty cycle contents $165 \mu \mathrm{m}$ (f) $80 \%$ duty cycle contents $136 \mu \mathrm{m}(\mathrm{g})$ and $90 \%$ duty cycle contents $117 \mu \mathrm{m}(\mathrm{h})$.

As the data shown in Table.7, the influence of pulse duty cycle variation was investigated on the metals percentage, deposits mass, thickness and current efficiency of the gold-copper heavy electrodeposition with current density of $6 \mathrm{~mA} / \mathrm{cm}^{2}$. Table. 7 shows that the percentage of gold-copper alloy $(74.4 \% \mathrm{Au}$ and $25.6 \% \mathrm{Cu})$ in the layer was acceptable and heavy electro-deposition rate increased significantly in the optimum duty cycle 
$(\theta=30 \%)$. This was confirmed by the results of influence of pulse duty cycle on the deposition rate compared to the calculated ones (Table.7). As duty cycle increased, deposition rate decreased. This was attributed to less amount of off-time at higher duty cycle [16]. Therefore, less time is provided for atoms to transfer to a stable position during off-time [22].

Table 6. Influence of duty cycle (\%) variation on pulse electro-deposition mass, deposition rate and composition of gold-copper alloy, and comparison of experimental values of the deposition thickness with calculated values.

\begin{tabular}{|c|c|c|c|c|c|c|c|c|c|c|}
\hline \multirow{2}{*}{$\begin{array}{l}\boldsymbol{\theta} \\
\%\end{array}$} & \multirow{2}{*}{$\begin{array}{c}\mathbf{m}_{\text {alloy }} \\
\text { (gr) }\end{array}$} & \multirow{2}{*}{$\begin{array}{l}I_{\text {avg }} \\
\left(\frac{\mathrm{mA}}{\mathrm{cm}^{2}}\right)\end{array}$} & \multicolumn{2}{|c|}{ Alloy (\%) } & \multirow{2}{*}{$\begin{array}{c}\mathbf{A} \\
\left(\mathbf{c m}^{2}\right)\end{array}$} & \multirow{2}{*}{$\begin{array}{l}\rho_{\text {alloy }} \\
\left(\frac{\mathrm{gr}}{\mathrm{cm}^{3}}\right)\end{array}$} & \multirow{2}{*}{$\begin{array}{c}\mathrm{T}_{\mathrm{th}} \\
(\boldsymbol{\mu} \mathrm{m})\end{array}$} & \multirow{2}{*}{$\begin{array}{l}T_{\text {avg }} \\
(\mu \mathrm{m})\end{array}$} & \multirow{2}{*}{$\begin{array}{c}\tau \\
(\min )\end{array}$} & \multirow{2}{*}{$\begin{array}{l}\mathbf{R}_{\text {avg }} \\
\left(\frac{\mu \mathbf{m}}{\min }\right)\end{array}$} \\
\hline & & & $\mathbf{A u}$ & $\mathrm{Cu}$ & & & & & & \\
\hline 10 & 0.127 & 6 & 733 & 267 & 1 & 14.49 & 88 & 82 & 240 & 0.363 \\
\hline 20 & 0.255 & 0.6 & 732 & 267 & 1 & 14.74 & 173 & 163 & 240 & 0.679 \\
\hline 30 & 0.313 & 0.6 & 744 & 256 & 1 & 14.90 & 210 & 202 & 240 & 0.841 \\
\hline 40 & 0.272 & 0.6 & 735 & 265 & 1 & 14.79 & 184 & 174 & 240 & 0.725 \\
\hline 50 & 0.254 & 0.6 & 727 & 273 & 1 & 14.65 & 174 & 167 & 240 & 0.695 \\
\hline 60 & 0.258 & 0.6 & 743 & 257 & 1 & 14.90 & 173 & 166 & 240 & 0.687 \\
\hline 70 & 0.254 & 0.6 & 731 & 269 & 1 & 14.74 & 172 & 165 & 240 & 0.683 \\
\hline 80 & 0.211 & 0.6 & 727 & 273 & 1 & 14.65 & 144 & 136 & 240 & 0.566 \\
\hline 90 & 0.185 & 0.6 & 740 & 260 & 1 & 14.91 & 124 & 117 & 240 & 0.487 \\
\hline
\end{tabular}

Electro-deposition with $30 \%$ duty cycle was selected as the optimal duty cycle due to the highest percentage of gold $(74.4 \%$ wt.) and its closeness to $75 \mathrm{wt} . \%$. Figure 5 shows the variations in the values of the various duty cycles with the percentage of gold in the treated layers.

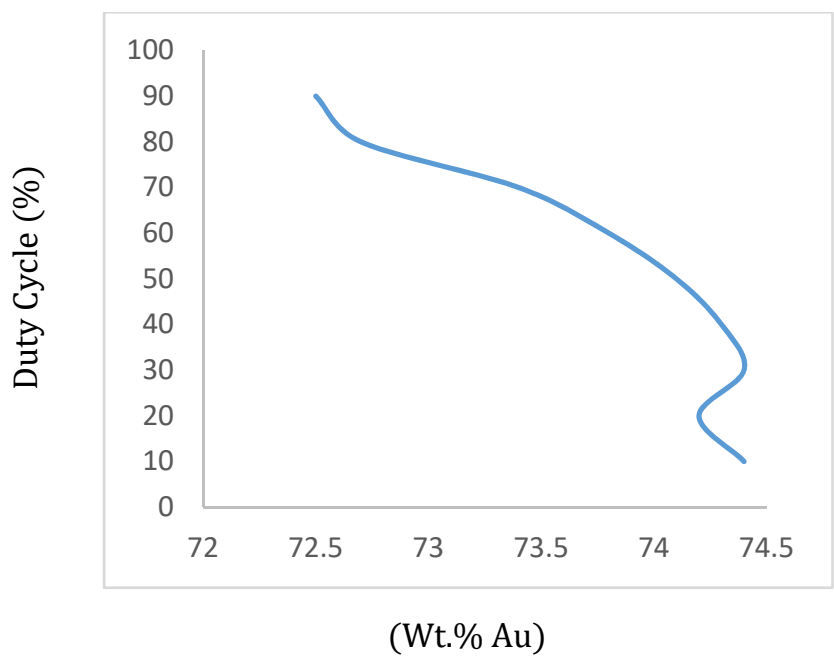

Fig. 5 The variations of various duty cycles on the percentage of gold in the Au-Cu layer

Figure 6 shows the variation of different values of the duty cycle with the deposition rate of the Au-Cu alloy in the deposited layers. 


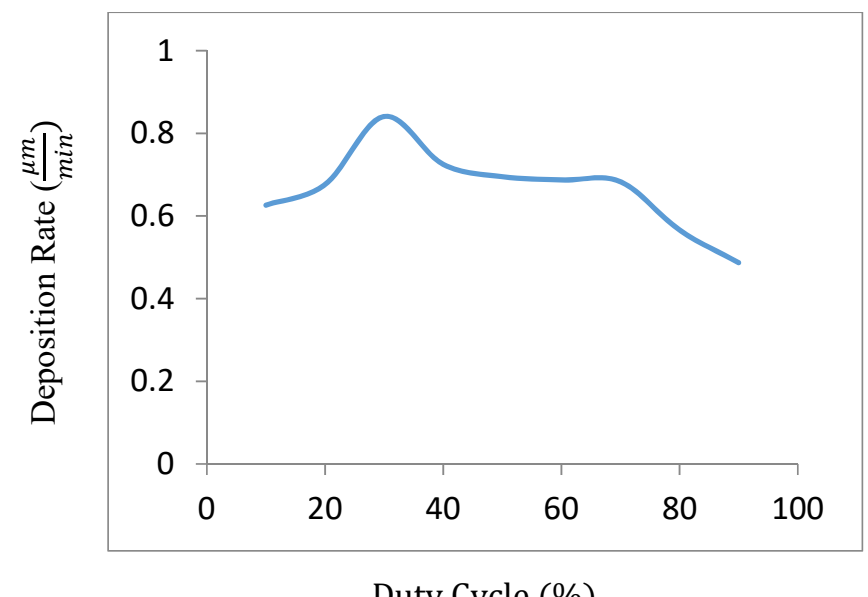

Fig. 6 The variations of different values of the duty cycles on the of Au-Cu electro-deposition rate.

As can be seen in Table 8, there were differences among the Au values in each sample. In case of the comparison of analytical techniques (ICP-OES and XRF), there was no statistical difference between the two methods regarding Au content, This means that using both equipment was possible to analyze the Au in gold alloys, but the ICP-OES apparatus was more accurate and precise than XRF method [23].

Table 7. Paired-data test between the results of ICP-OES and XRF techniques for Au content.

\begin{tabular}{c|c|c|c}
\hline \multirow{2}{*}{ \% Duty Cycle } & \multicolumn{2}{|c|}{ Au (part per thousand) } & \multirow{2}{*}{$\begin{array}{c}\text { Paired Test ICP-OES } \\
\text { and XRF Differences }\end{array}$} \\
\cline { 2 - 3 } & ICP-OES & XRF & \\
\hline Direct Current & 744.1 & 742.0 & 1.7 \\
20 & 739.9 & 739.7 & 0.2 \\
30 & 732.3 & 729.9 & 2.4 \\
40 & 744.8 & 749.6 & -4.8 \\
50 & 735.4 & 741.4 & -6.0 \\
60 & 726.9 & 740.0 & -13.1 \\
70 & 743.6 & 740.3 & 3.3 \\
80 & 731.2 & 746.1 & -14.9 \\
90 & 726.6 & 735.0 & 8.4 \\
& 739.8 & 745.1 & 5.3 \\
\end{tabular}

\section{CONCLUSIONS}

According to the results of this study, obtaining the necessary thickness of gold-copper electro-deposited layers for making gold alloy artifacts was possible to be faster rather than conventional D.C. electro-deposition by using pulse current. Pulse electrodeposition of gold-copper was a repeatable and controllable technique to prepare a layer with a certain composition of gold and copper. In this method, the pulse parameters (duty cycle percentage and average current density) and operation condition (gold and cyanide concentration, temperature, $\mathrm{pH}$ and agitation of the alloy gold bath) variations` effects were investigated. In heavy electro-deposition of gold-copper, LDAO could be used as a suitable surfactant to provide a thick gold alloys deposit at acceptable karat and deposition rates. It was found that at pulse current density by the constant value of $6\left(\frac{\mathrm{mA}}{\mathrm{cm}^{2}}\right)$ and $30 \%$ duty cycle, the best amount of gold was obtained and highest rate of deposited layer was observed on the silver cathodes. 
Duty cycles above $30 \%$ led to lower rates of the depositions. Also, it has been observed that the experimental deposition rate and current efficiency of D.C. electrodepositions were lower than those of pulse electro-deposition. In order to improve the \%weight of gold in deposited layers, it was recommended to apply this method with goldsilver.

\section{ACKNOWLEDGEMENTS}

We gratefully acknowledge the invaluable support provided by Phoenix Yassin Chemistry Co., Research \& Development lab for precious Metals.

\section{References}

[1] Costa JD, de Sousa MB, Alves JJN, Evaristo BO, Queiroga RA, Santos AX, Maciel TM, Campos ARN, de Santana RAC, Prasad S. Effect of Electrochemical Bath Composition on the Preparation of Ni-W-Fe-P Amorphous Alloy. Int. J. Electrochem. Sci., 13 (2018) $2969-2985$

[2] The electroforming of gold and its alloys, Anselm T. Kuhn \& Leslive V. Lewise faculty of Science \& Technology, Harrow College, Harrow HAI 3TP, U.K. B.J.S. Electroforming Ltd., London NW6, U.K.

[3] Huo B, Tong S, Li Y. Adaptive fuzzy fault-tolerant output feedback control of uncertain nonlinear systems with actuator faults. International Journal of Systems Science 2013; 44 (12): 2365-2376.

[4] Robert S. Catanzaro, Steven J. lacono, "Method of electroforming a gold jewelry article." U.S. Patent 5,393,405, issued August 1, 1993.

[5] Bright Gold Electroplating Solutions, Guy Bacquias, Consultant, Béthune, France.

[6] Electrochemical behavior of gold alloy and composite plating bath, B. Bozzini, P.L. Cavallotti,b and G. Giovannellib.

[7] Frank H. Reid, William Goldie. Electrochemical Publication 1td., Dec 1, 1974- Technology.

[8] Kinetics of electrodeposition of silver and copper at template synthesis of nanowiresp. G. Globa, E.A.Zasavitsky, V.G.Kantser, S.P.Sidelinikova, A.I.Dikusar.

[9] Canning W, The Canning Handbook of Surface Finishing Technology (CBS publishers and Distributors, New Delhi) 2005.

[10] Nasser Kanani, Electroplating-Basic Principles, Processes and Practice (Elsevier Ltd., Berlin, Germany), 2004.

[11] Study of surface morphology in DC and pulse plating of silver alloy, C Shanthia, S Barathanb, Rajasrisen Jaiswala \& R M Arunachalamc

[12] The Electrodeposition of Gold by Pulse Plating, Ch. J. Raub and A. Knödler Forschungsinstitut für Edelmetalle und Metallchemie, Schwäbisch Gmünd, West Germany

[13] Kuo CG, Hsu CY, Chen JH, Lee PW. Discharge current effect on machining characteristics and mechanical properties of aluminum alloy 6061 workpiece produced by electric discharging machining process. Advances in Mechanical Engineering, $2017 ; 9(11): 1-8$.

[14] Kolli M, Kumar A. Effect of dielectric fluid with surfactant and graphite powder on Electrical Discharge Machining of titanium alloy using Taguchi method. Engineering Science and Technology, an International Journal. 2015; 8 (4): 524-535.

[15] Jean-Claude Puippe \& Frank Leaman, Theory and practice of pulse plating, (American electroplaters and surface finishers Society, Orlando, Florida), 1986, 159-171.

[16] Erb U, Nanostruct Mater, 6 (1995) 533.

[17] Electroplating Nanostructured Hard Gold through the Pulse Galvanostatic Method Hassan Karami, Hamid Babaei, and Int. J. Electrochem. Sci., 7 (2012) $601-614$

[18] Determination of gold in gold jewellery alloys by ICP spectrometry, M. Brill, K-H. Wiedemann, W C. Heraeus GmbH, Hanau, Germany.

[19] Donald W. Thomson, "Gold alloy plating compositions and method." U.S. Patent 4,179,344, issued July 2, 1973.

[20] Electrokinetic behavior of gold alloy and composite plating baths. "INFM, Dipartimento di Ingegneria dell'lnnovazione, Universith di Lecce, Lecce, Italy, Dipartimento diChimica Fisica Applicata, Politecnico di Milano, Milan, Italy

[21] Gold Plating Technology, Frank H. Reid, William Goldie. Electrochemical Publications Ltd, 01 Jun 1987

[22] Sajjadnejad M, Omidvar H, Javanbakht M. Influence of Pulse Operational Parameters on Electrodeposition, Morphology and Microstructure of Ni/nanodiamond Composite Coatings. Int. J. Electrochem. Sci., 12 (2017) 3635 - 3651, doi: 10.20964/2017.05.52

[23] Comparison of ICP-OES and XRF Performance for Pb and As Analysis in Environmental Soil Samples from Chihuahua City, Mexico. Delgado R. Marcos1, Parsons Jason, Garcia Humberto,Corral A. Alba Y., Cruz J. Gustavo, Campos T. Alfredo, Duarte M. Alberto, Gardea-Torresdey Jorge. Physical Review \& Research International 29-44, 2011 